

Edukatif : Jurnal Ilmu Pendidikan Volume 4 Nomor 1 Tahun 2022 Halm 1487 - 1497

EDUKATIF: JURNAL ILMU PENDIDIKAN

Research \& Learning in Education

https:/ledukatif.org/index.php/edukatif/index

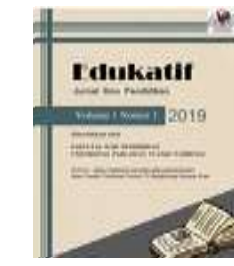

\title{
Perancangan Media Pembelajaran Topologi Jaringan dengan Augmented Reality di Program Studi Teknik Informatika
}

\author{
Diki Arisandi $^{1 凶}$, Debi Setiawan ${ }^{2}$, Karpen $^{3}$, Muhammad Musyafak ${ }^{4}$ \\ Universitas Abdurrab Pekanbaru, Indonesia ${ }^{1,2,4}$ \\ STMIK Amik Riau, Indonesia ${ }^{3}$

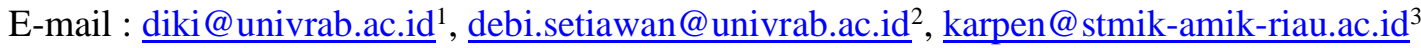 \\ muhammad.musyafak@student.univrab.ac.id ${ }^{4}$
}

\begin{abstract}
Abstrak
Perkembangan teknologi saat ini dapat dilihat pada bidang pendidikan diantaranya memanfaatkan augmented reality (AR) untuk membuat media pembelajaran. Mahasiswa program studi teknik informatika di Universitas Abdurrab mengalami kesulitan pada materi di matakuliah jaringan komputer, yaitu pembahasan tentang Topologi jaringan. Sebelumnya, pembahasan tentang topologi hanya didapat dari buku teks, slide presentasi, dan internet. Hasilnya, mahasiswa kurang memahami materi tentang topologi dan implementasinya. Hasil pretest yang dikerjakan oleh mahasiswa mendapat nilai rata-rata 58,8. Berdasarkan hasil pre test, peneliti membuat rancangan simulasi topologi jaringan komputer berbasis AR menggunakan Vuforia dan Unity 3D, kemudian melakukan pengujian sebanyak dua fase, yaitu fase alfa dan fase beta. Fase alfa dengan menggunakan metode blackbox sukses dilaksanakan, lalu pengujian pada fase beta dengan melibatkan reponden dan pertanyaan yang sama menunjukkan peningkatan dengan rata-rata skor sebesar 80,6. Dengan hasil yang dicapai, bisa dikatakan bahwa pembuatan media pembelajaran berbasis AR dapat membantu mahasiswa untuk memahami materi tentang simulasi topologi jaringan.
\end{abstract}

Kata Kunci: augmented reality, topologi, media pembelajaran, simulasi, jaringan komputer.

\begin{abstract}
Today's development of technology can be found in the educational field, such as utilizing augmented reality (AR) to build instructional media. The Students of informatics engineering at Abdurrab University have difficulty in one of the materials in computer networking courses, namely the network topology. Previously, this material was only obtained from textbooks, presentation slides, and the internet. As a result, students do not fully understand the material regarding the topology and its implementation. The average score acquired by students was 58.8 based on their pre-test. From the results, researchers developed a simulation design of ARbased computer network topology using Vuforia and Unity 3D, then conducted two phases of testing, namely alpha phase and beta phase. The alpha phase using the BlackBox method was successfully implemented, then testing in the beta phase involving the same respondents and question showed an increase with the average score of the test was 80,6. By the results achieved, it concluded that the AR-based instructional media was able to support the students to understand a network topology simulation material.
\end{abstract}

Keywords: augmented reality, topology, instructional media, simulation,computer networking.

Copyright (c) 2022 Diki Arisandi, Debi Setiawan, Karpen, Muhammad Musyafak

$\triangle$ Corresponding author:

Email: diki@univrab.ac.id

DOI : https://doi.org/10.31004/edukatif.v4i1.2231

ISSN 2656-8063 (Media Cetak)

ISSN 2656-8071 (Media Online)

Edukatif : Jurnal Ilmu Pendidikan Vol 4 No 1 Tahun 2022 p-ISSN 2656-8063 e-ISSN 2656-8071 
1488 Perancangan Media Pembelajaran Topologi Jaringan dengan Augmented Reality di Program Studi Teknik Informatika - Diki Arisandi, Debi Setiawan, Karpen, Muhammad Musyafak

DOI: https://doi.org/10.31004/edukatif.v4i1.2231

\section{PENDAHULUAN}

Perkembangan dunia teknologi informasi mengalami peningkatan khususnya pada bidang pendidikan, dimana teknologi digunakan pada setiap kegiatannya (Nissa \& Renoningtyas, 2021). Sebelum memasuki tahun 1990, sumber bacaan untuk belajar hanya bisa didapat dari buku-buku (Indrajit, 2000). Namun setelah tahun 1990, dimana penetrasi internet mulai masuk ke Indonesia (Krisnawati, 2018), sumber belajar tidak lagi hanya dari buku, namun bisa didapat dari internet walaupun penggunaannya pada saat itu belum seperti saat ini, dimana akses internet dapat dinikmati oleh siapa saja dan kapan saja. Survey dari APJII (Asosiasi Penyelenggara Jasa Internet Indonesia) yang dirilis setiap tahun menyatakan bahwa penetrasi internet saat ini tidak hanya untuk kalangan tertentu dan wilayah tertentu saja, namun sudah bisa diakses oleh siapa saja dan kapan saja (Adiarsi, Stellarosa, \& Silaban, 2015), bahkan ragam perangkat yang dapat mengakses internet tidak sebatas komputer atau laptop, namun juga smartphone (Art., 2017).

Penetrasi internet saat ini juga berdampak kepada pendidikan, internet menawarkan fleksibilitas tanpa harus terkendala ruang dan waktu. Dengan ini, media pembelajaran tidak hanya terbatas pada buku namun juga lewat internet. Hal ini juga ditunjang kemajuan teknologi saat ini dimana teknologi proyektor memungkinkan seorang Guru atau Dosen membuat materi pembelajaran dalam bentuk slide yang interaktif. Penggunaan teknologi pembelajaran dapat bervariasi, mulai dari teknologi yang umum seperti penggunaan aplikasi perkantoran (Nugraha, Nur'aeni, Suryana, \& Muharram, 2021), teknologi berbasis online melalui aplikasi berbasis internet, atau dapat juga berbasis teknologi realita semu. Salah satu pembelajaran yang berbasis realita semu adalah augmented reality (AR).

AR adalah sebuah variasi dari virtual environment atau yang lebih dikenal sebagai virtual reality (Damardono \& Kautsar, 2020). AR memungkinkan pengguna melihat secara nyata terkait sebuah objek yang diamati (Kurniawan, 2012), namun kehadiran objek tersebut sebenarnya adalah semu atau dalam artian tidak benar-benar nyata kehadirannya (Oka, 2017). AR merupakan pengembangan dari teknologi tiga dimensi (3D) yang diproses menggunakan rekayasa grafis beresolusi tinggi sehingga menghasilkan objek yang hampir bahkan sama dengan aslinya (Adiputri, Fauzan, \& Riza, 2020). Teknologi AR dapat menambahkan realita pada dunia nyata disertai unsur obyek virtual, dimana batas antara dunia maya dan nyata seolah-olah tidak ada (Ernawati, Hidayat, \& Rahmatulloh, 2017). AR menggabungkan benda-benda nyata dan maya di lingkungan nyata, berjalan secara interaktif dalam waktu nyata, dan terdapat integrasi antar benda dalam tiga dimensi, yaitu benda maya terintegrasi dalam dunia nyata (Masri \& Lasmi, 2018). Perpaduan benda maya dan nyata dimungkinkan dengan teknologi tampilan yang sesuai, interaktivitas dilakukan melalui perangkat-perangkat masukan tertentu, dan integrasi yang baik memerlukan penjejakan yang efektif (Uliontang, Setyati, \& Chandra, 2020).

Media pembelajaran berbasis AR memungkinkan untuk diterapkan diberbagai level pendidikan, salah satunya adalah pendidikan tinggi. Beberapa riset terdahulu sudah memaparkannya terkait dengan penerapan AR dalam media pembelajaran. Mustika dkk. ditahun 2015 dalam penelitiannya berjudul Implementasi Augmented Reality Sebagai Media Pembelajaran Interaktif memaparkan hasil pemanfaatan AR dalam pembelajaran Organiasi Arsitektur Komputer di STMIK Palcomtech. Pada umumnya, Dosen menggunakan media konvensional seperti slide Powerpoint yang ditampilkan melalui projektor dan media lainnya. Namun berdasarkan survey kepada mahasiswa, media yang digunakan dalam belajar dinilai kurang menarik, dan berpengaruh kepada kurang pemahamannya mahasiswa terhadap materi yang disampaikan oleh dosen khususnya terkait pemahaman tentang komponen-komponen komputer. Berdasarkan situasi yang ada, maka dirancang media pembelajaran berbasis AR untuk pengenalan komponen komputer. Setelah diadakan pengujian alfa dan beta, aplikasi yang dirancang dapat digunakan untuk mendukung pembelajaran Organiasi Arsitektur Komputer (Mustika, Ceppi Gustiar, Rheno, \& Sofyan, 2015). 
1489 Perancangan Media Pembelajaran Topologi Jaringan dengan Augmented Reality di Program Studi Teknik Informatika - Diki Arisandi, Debi Setiawan, Karpen, Muhammad Musyafak

DOI: https://doi.org/10.31004/edukatif.v4i1.2231

Penelitian dari Kamelia tahun 2015 juga menjelaskan tentang pemanfaatan AR dalam pembelajaran, dalam hal ini pembelajaran Kimia dasar, khususnya untuk bahasan struktur atom dan molekul. Kesulitan memvisualisasikan atom dan molekul, sistem periodik, ikatan kimia, hidrokarbon dan beberapa materi lainnya menyebabkan mahasiswa mengalami kesulitan dalam belajar matakuliah Kimia dasar. Bersadarkan analisis tersebut, maka dirancang sebuah media pembelajaran berbasis AR yang realistis untuk menggambarkan materi terkait atom dan moelkul agar mahasiswa dapat belajar lebih efektif. Setelah implementasi yang dilakukan terhadap media pembelajaran berbasis AR, mahasiswa dapat belajar tentang struktur atom dan molekul dengan lebih baik dari sebelumnya (Kamelia, 2019).

Penelitian selanjutnya dari Anggraini dkk. tahun 2018 memaparkan tentang Pembelajaran Pengukuran Listrik Berbasis AR pada Mahasiswa Teknik Elektro UNIPMA. Materi tentang pengukuran listrik menjadi hal yang fundamental bagi mahasiswa Teknik Elektro, maka dari itu untuk mendukung pembelajaran agar lebih mudah dimengerti, perlu ada media berbasis AR yang dapat menambah citra sintetis kedalam lingkungan nyata pembelajaran materi pengukuran listrik. Hal ini dimaksudkan untuk membantu mahasiswa agar tidak kesulitan dalam membayangkan komponen-komponen elektro yang sedang dipelajari. Setelah media pembelajaran dirancang, diadakan sebuah survey untuk menganalisa kelayakan rancangan media pembelajaran. Hasil survey yang didapat menunjukkan bahwa rancangan teknologi AR dalam pembelajaran pengukuran listrik dinilai sangat layak untuk digunakan dalam pembelajaran (Anggraini \& Sunaryantiningsih, 2018).

Terkait dengan pembelajaran komputer, Endra dan Agustina memaparkan bahwa teknologi AR juga bisa dimanfaatkan untuk mendukung pembelajaran mahasiswa pada matakuliah Pengantar Teknologi Informasi dan Komunikasi di Fakultas Ilmu Komputer Universitas Bandar Lampung. Teknologi AR yang digunakan yaitu dengan memanfaatkan marker sebagai penanda objek, jika marker dilihat menggunakan kamera maka akan muncul komponen perangkat keras pada komputer. Berdasarkan pengujian menggunakan blackbox testing dan whitebox testing, media pembelajaran yang dirancang dinilai sesuai dan dapat dipergunakan untuk mendukung pembelajaran (Endra \& Agustina, 2019).

Teknologi AR menjadi salah satu pembahasan dalam rumpun ilmu komputer, termasuk pada program studi teknik infomatika. Selain penguasaan aspek komputasi dan pemograman, aspek komunikasi data dan jaringan menjadi hal yang wajib dikuasai mahasiswa jurusan teknik informatika. Hingga saat ini, pemanfaatan teknologi AR dalam perkuliahan teknik informatika belum banyak dilakukan. Berdasarkan kajian terdahulu, pemanfaatan AR baru sebatas untuk pengenalan periferal atau perangkat keras pada komputer. Sebagai salah satu mata kuliah yang berkaitan dengan perangkat keras, perlu adanya sebuah media pembelajaran yang tidak hanya bersumber dari buku saja, apalagi jika nanti sudah terkait dengan materi yang berkaitan dengan pembahasan infrastruktur jaringan, yang mengharuskan mahasiswa berkreasi dan berfikir imajinatif dalam menyelesaikan perancangan infratruktur jaringan.

Salah satu pembahasan terkait infrastruktur jaringan adalah teori tentang topologi jaringan itu sendiri. Media pembelajaran yang tersedia tentang topik ini lebih dominan didapat dari buku teks yang menyebabkan mahasiswa, terutama mahasiswa pada program studi Teknik Informatika Universitas Abdurrab mengalami kesulitan untuk bisa memahami dan memvisualisasikan secara utuh terkait ragam topologi yang disebutkan sebelumnya. Hal ini menyebabkan pemahaman tentang topologi hanya sebatas teori dan akan berdampak kepada penguasaan materi selanjutnya, yaitu perancangan infrastruktur jaringan.

Berdasarkan beberapa kajian terdahulu, peneliti membuat rancangan simulasi topologi jaringan dengan menggunakan AR. Pada awal matakuliah jaringan komputer, terdapat sub pembahasan tentang topologi jaringan. Topologi jaringan merupakan metode yang memungkinkan penggunanya untuk menghubungkan suatu komputer dengan komputer lainnya dalam suatu jaringan. Beberapa topologi yang ada diantaranya yaitu topologi ring, topologi bus, topologi star, topologi tree dan topologi mesh. Dengan adanya analisis yang telah diuraikan sebelumnya, peneliti membuat rancangan simulasi ragam topologi jaringan komputer dan contoh 
1490 Perancangan Media Pembelajaran Topologi Jaringan dengan Augmented Reality di Program Studi Teknik Informatika - Diki Arisandi, Debi Setiawan, Karpen, Muhammad Musyafak

DOI: https://doi.org/10.31004/edukatif.v4i1.2231

penerapan tiap topologi yang berbasis AR. Berbeda dengan hasil penelitian terdahulu, Hasil rancangan simuliasi dalam penelitian ini harus pula diujikan sebelum digunakan pada mahasiswa program studi Teknik Informatika sebanyak dua fase pengujian.

Pengujian rancangan AR dalam bentuk simulasi ini sangat penting dilakukan, sebab sebuah simulasi harus bisa menggambarkan atau mewakili keadaan seperti aslinya. Sehingga dalam penelitian ini selain pengujian hasil masukan dan luaran, pengujian juga harus dilakukan dengan melibatkan pengguna agar rancangan AR dapat benar-benar diimplementasikan dan dimanfaatkan untuk kegiatan pembelajaran. Hasil dari penelitian ini tentunya diharapkan dapat membantu mahasiswa dalam memahami topologi jaringan dan implementasinya dilapangan. Sehingga mahasiswa dapat terbantu dalam memahami materi selanjutnya, yaitu tentang perancangan infrastruktur jaringan.

\section{METODE PENELITIAN}

Penelitian ini diadakan di Universitas Abdurrab, khususnya program studi Teknik Informatika. Penelitian ini diadakan selama kurang lebih delapan bulan dari mulai hingga selesai penelitian. Pada penelitian ini, di perlukan susunan kerangka kerja (framework) yang jelas tahapan-tahapannya. Kerangka kerja ini merupakan langkah-langkah yang akan dilakukan dalam penyelesaian masalah yang dibahas. Peneliti memilih kerangka kerja secara sekuensial atau berurut dengan maksud agar pengerjaan lebih terarah dan teratur. Selain itu, proses pengerjaan penelitian tidak akan beranjak ketahap berikutnya jika masih ada pengerjaan ditahap sebelumnya yang belum selesai. Adapun kerangka kerja yang digunakan ialah sebagai berikut:

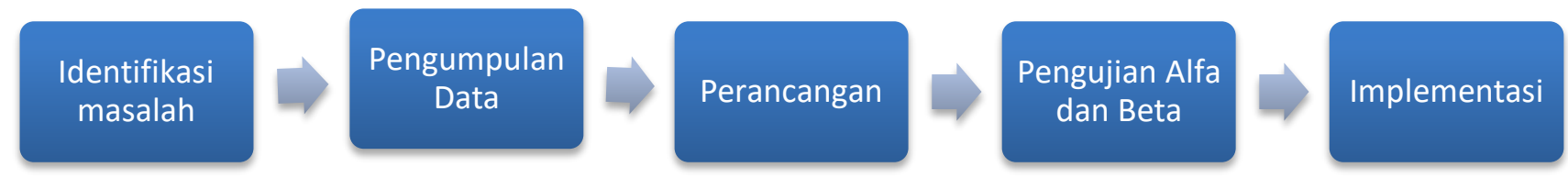

Gambar 1. Kerangka Kerja Penelitian

1. Identifikasi masalah

Pada tahap ini penulis melakukan identifikasi masalah pada proses pembelajaran yang berjalan guna mengetahui permasalahan dan kebutuhan yang harus dipenuhi, yaitu dengan cara melakukan observasi yang dihadapi mahasiswa dalam pelaksanaan perkuliahan pada matakuliah Jaringan Komputer. Permasalahan yang menjadi fokus peneliti yaitu kurangnya pemahaman mahasiswa terkait bagaimana memvisualisasikan secara nyata jenis topologi jaringan yang diajarkan serta bagaimana implementasinya dilapangan, sementara media belajar yang ada hanya bersumber dari buku, slide powerpoint, dan internet. Sumber bacaan yang telah disebutkan sebelumnya tidak berupa dalam bentuk yang nyata secara 3D, namun hanya dalam bentuk bagan ataupun jika ada yang berbentuk riil hanya dalam format dua dimensi (2D).

2. Pengumpulan data

Pengumpulan data dilakukan dengan cara menyebarkan kuesioner kepada mahasiswa yang mengambil matakuliah jaringan komputer. Pengumpulan data dilakukan sebanyak dua kali, saat sebelum dan sesudah media pembelajaran berbasis AR dirancang. Pertanyaan yang diajukan terkait seputar pemahaman tentang pemahaman materi topologi jaringan sebanyak 16 soal. Jumlah populasi mahasiswa yang ada sebanyak 120 orang, yang kemudian diambil sampel nya secara purposive sebanyak 92 orang berdasarkan persamaan slovin (1) (Riyanto \& Hatmawan, 2020). Penyebaran kuesioner dilakukan secara purposive, yang menekankan berdasarkan kriteria-kriteria tertentu dengan tujuan mendapatkan dapat memecahkan permasalahan penelitian serta dapat memberikan nilai yang lebih representatif sesuai dengan harapan peneliti (Ananda \& Fadhli, 2018). Target sampel dari populasi yang ada yakni mahasiswa yang pernah atau sedang mengambil mata kuliah jaringan komputer. 
1491 Perancangan Media Pembelajaran Topologi Jaringan dengan Augmented Reality di Program Studi Teknik Informatika - Diki Arisandi, Debi Setiawan, Karpen, Muhammad Musyafak

DOI: https://doi.org/10.31004/edukatif.v4i1.2231

$$
n=\frac{N}{1+N e^{2}}
$$

3. Perancangan

Berdasarkan hasil dari indentifikasi dan pengumpulan data, maka dilakukan perancangan AR. Perancangan topologi AR menggunakan beberapa tools diantaranya yaitu Unity 3D dan Vuforia SDK. Untuk merancang objek marker, peneliti menggunakan tools Vuforia SDK, yaitu sebuah aplikasi khusus dibidang computer vision untuk mendesain rancangan AR maupun VR (virtual reality). Sedangkan aplikasi Unity 3D dipergunakan peneliti untuk menggabungkan hasil desain dari Vuforia SDK dan memberi efek animasi lalulintas data pada simulasi topologi jaringan yang dirancang.

4. Pengujian alfa dan beta

Setelah mendesain dan merancangan media pembelajaran topologi jaringan, maka perlu diadakan pengujian sebelum digunakan dan diimplementasikan. Pengujian yang dilakukan terdiri atas dua fase, yaitu fase alfa dan fase beta. Pengujian Fase alfa dilakukan dengan menggunakan teknik Blackbox testing, yaitu sebuah metode yang memeriksa hasil masukan dan hasil luaran dari aplikasi yang dirancang (Salamun, Arisandi, Elvitaria, \& Trisnawati, 2021) seperti terlihat pada gambar 2 berikut:


Gambar 2. Blackbox Testing Pada Fase Alfa

Jika pengujian fase alfa telah menghasilkan luaran yang diharapkan, aplikasi simulasi diuji kembali pada fase beta. Fase beta merupakan sebuah pengujian yang melibatkan orang atau pihak yang berkepentingan untuk mengetes kesesuaian dan pemahamannya terhadap suatu aplikasi atau sistem (Salamun, Arisandi, Sukri, et al., 2021) seperti yang terlihat pada gambar 3 berikut:

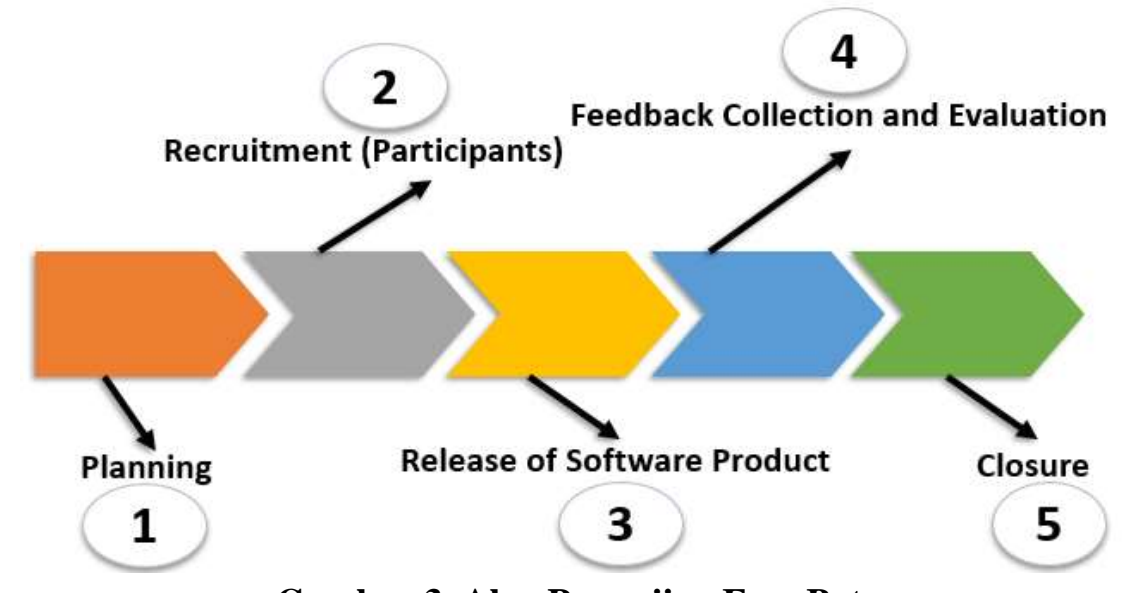

Gambar 3. Alur Pengujian Fase Beta 
1492 Perancangan Media Pembelajaran Topologi Jaringan dengan Augmented Reality di Program Studi Teknik Informatika - Diki Arisandi, Debi Setiawan, Karpen, Muhammad Musyafak

DOI: https://doi.org/10.31004/edukatif.v4i1.2231

Pada fase beta ini, peneliti membuat skenario perencanaan untuk pengujian simulasi berbasis AR dengan merekrut partisipan. Dalam hal ini, peneliti akan memberikan pertanyaan serupa terkait dengan topologi jaringan sebanyak 16 soal yang sama dengan pertanyaan sebelumnya, sebagai bentuk dari feedback yang hasilnya akan dikumpulkan dan dianalisa sehingga peneliti mendapat gambaran hasil sebelum menggunakan AR dan sesudah menggunakan AR. Pihak yang menjadi responden adalah mahasiswa yang juga telah diminta kesediaanya dalam partisipasi sebelumnya yang berjumlah 92 orang.

5. Implementasi.

Aplikasi simulasi topologi jaringan komputer yang telah melewati fase alfa dan beta tentunya telah bebas dari kesalahan dan telah dievaluasi kelayakannya. Maka aplikasi simulasi topologi jaringan komputer dapat dipergunakan untuk kegiatan belajar mahasiswa program studi Teknik Informatika Universitas Abdurrab. Harapannya adalah simulasi topologi yang dibangun dapat dimanfaatkan sebagai media pembelajaran untuk membantu mahasiswa dalam memahami topogi jaringan.

\section{HASIL DAN PEMBAHASAN PENELITIAN}

Sebelum merancang simulasi topologi jaringan, peneliti melakukan pre test untuk mengetahui sejauh mana pemahaman tentang topologi jaringan. Peneliti membagikan 16 pertanyaan yang dijawab 92 mahasiswa. Dari 16 soal yang dikerjakan, didapat hasil nilai rata-rata keseluruhan yaitu sebesar 58,8 dan nilai rata-rata perjawaban dapat dilihat pada gambar 4 berikut:

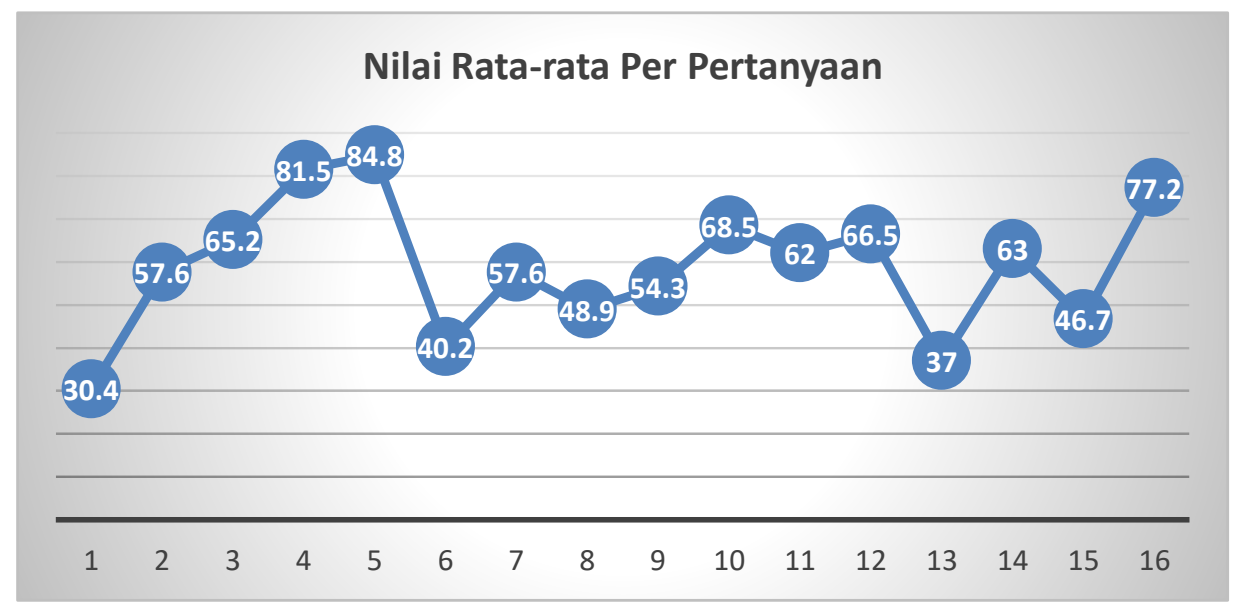

Gambar 4. Nilai Rata-Rata Pre Test Per Pertanyaan

Berdasarkan gambar 1, maka dapat disimpulkan bahwa responden memiliki pemahaman yang kurang memuaskan tentang topologi jaringan. Hal ini disebabkan karena masih ada item pertanyaan yang memiliki nilai rata-rata dibawah 60 sebanyak 7 item pertanyaan, atau 50\% dari total pertanyaan yang diberikan.

Peneliti kemudian melakukan perancangan simulasi topologi jaringan dengan berbasis AR. Didalam sistem Topologi Jaringan Berbasis AR terdapat object yang akan di 3D-kan seperti topologi bus, ring, star, tree dan mesh seperti terlihat pada gambar 5. 
1493 Perancangan Media Pembelajaran Topologi Jaringan dengan Augmented Reality di Program Studi Teknik Informatika - Diki Arisandi, Debi Setiawan, Karpen, Muhammad Musyafak

DOI: https://doi.org/10.31004/edukatif.v4i1.2231

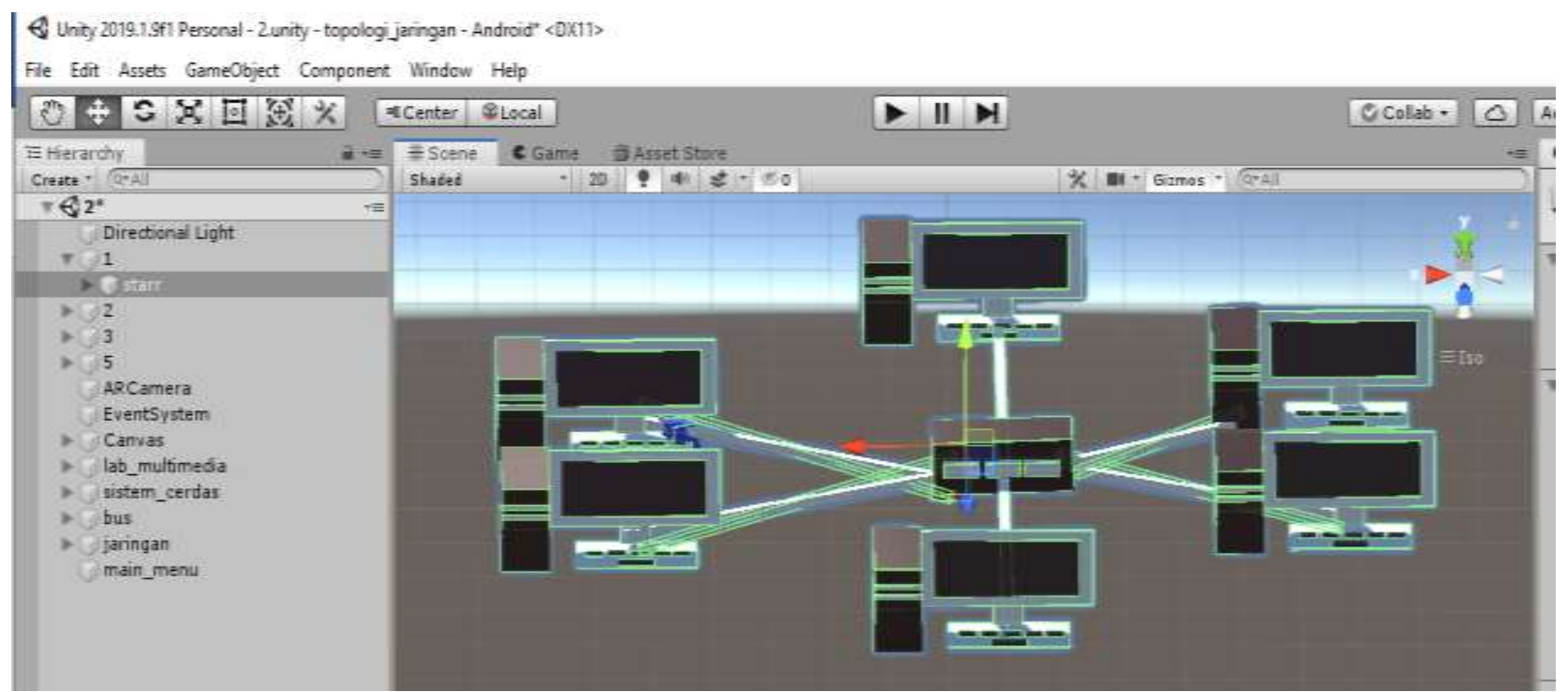

\section{Gambar 5. Rancangan Animasi Simulasi Salah Satu Topologi}

Selain topologi-topologi tersebut, pada gambar 3 peneliti mendesain penerapan beberapa topologi yang berada di laboratorium komputer pada Universitas Abdurrab: yaitu lab jaringan, lab multimedia dan lab sistem cerdas. Pengambilan topologi dilab bermaksud agar mahasiswa daapt memahami implementasi topologi yang nyata atau jaringan yang sudah berjalan menggunakan topologi yang ada.



\section{Gambar 6. Rancangan Animasi Simulai Topologi Pada Salah Lab Jaringan}

Setelah seluruh rancangan simulasi jaringan selesai, peneliti melakukan pengujian alfa dengan metode blackbox untuk melihat apakah hasil masukan telah sesuai dengan hasil luaran yang diinginkan. Pengujian menggunakan kamera dari smartphone android pada gambar marker yang ada untuk menguji hasil luaran. Selain luaran, pengujian kali ini juga menguji ambang batas toleransi kemiringan dari marker-marker yang ada. Adakalanya marker yang telah dibuat tidak jelas ditangkap oleh kamera, sehingga objek 3D dari simulasi tidak bisa tampil. Namun ada juga suatu kondisi dimana marker dapat tertangkap oleh kamera namun posisi kamera harus tegak lurus dengan marker, sehingga proses pembacaan objek tidak bisa fleksibel. Peneliti mengadakan pengujian ini dengan tujuannya agar dapat mengetahui sejauh mana kejelasan dari kamera untuk melihat marker yang ada jika posisi kamera tidak berada tegak sejajar dengan marker, sekaligus menguji kesesuaian hasil yang ditampilkan. Hasil pengujian dapat dilihat pada tabel 1 berikut. 
1494 Perancangan Media Pembelajaran Topologi Jaringan dengan Augmented Reality di Program Studi Teknik Informatika - Diki Arisandi, Debi Setiawan, Karpen, Muhammad Musyafak

DOI: https://doi.org/10.31004/edukatif.v4i1.2231

Tabel 1

Hasil Masukan Dan Luaran Berikut Ambang Batas Kemiringan Marker

\begin{tabular}{ccccc}
\hline No & Marker & $\begin{array}{c}\text { Batas Toleransi } \\
\text { Kemiringan }\end{array}$ & Hasil Scan Marker & $\begin{array}{c}\text { Menampilkan } \\
\text { Objek 3D }\end{array}$ \\
\hline 1 & Topologi Bus & $60 \%$ & & $\begin{array}{c}\text { Tampil [ } \sqrt{ }] \\
\text { Tidak [ }]\end{array}$ \\
& & & & \\
\end{tabular}

\begin{tabular}{llll}
\hline 2 & Topologi Ring & $60 \%$ & Tampil [ $]$ \\
Tidak [ ]
\end{tabular}

\begin{tabular}{llll}
\hline 3 & Topologi Mesh & $65 \%$ & Tampil [ $]$ T \\
Tidak [ $]$
\end{tabular}

Pengujian berikutnya adalah beta testing terhadap responden yang sama. Pengujian ini bertujuan untuk mengetahui pemahaman mahasiswa tentang topologi jaringan dan implementasinya. Responden diminta menggunakan aplikasi ini selama satu jam dan mempelajari konten-konten yang tersedia. Setelah itu, 
1495 Perancangan Media Pembelajaran Topologi Jaringan dengan Augmented Reality di Program Studi Teknik Informatika - Diki Arisandi, Debi Setiawan, Karpen, Muhammad Musyafak

DOI: https://doi.org/10.31004/edukatif.v4i1.2231

mahasiswa diminta kembali menjawab soal yang sama sebagai bentuk post test untuk mengetahui sejauh mana pemahaman tentang materi topologi jaringan. Perbandingan hasil dari pre test dan post test dapat dilihat pada grafik berikut:

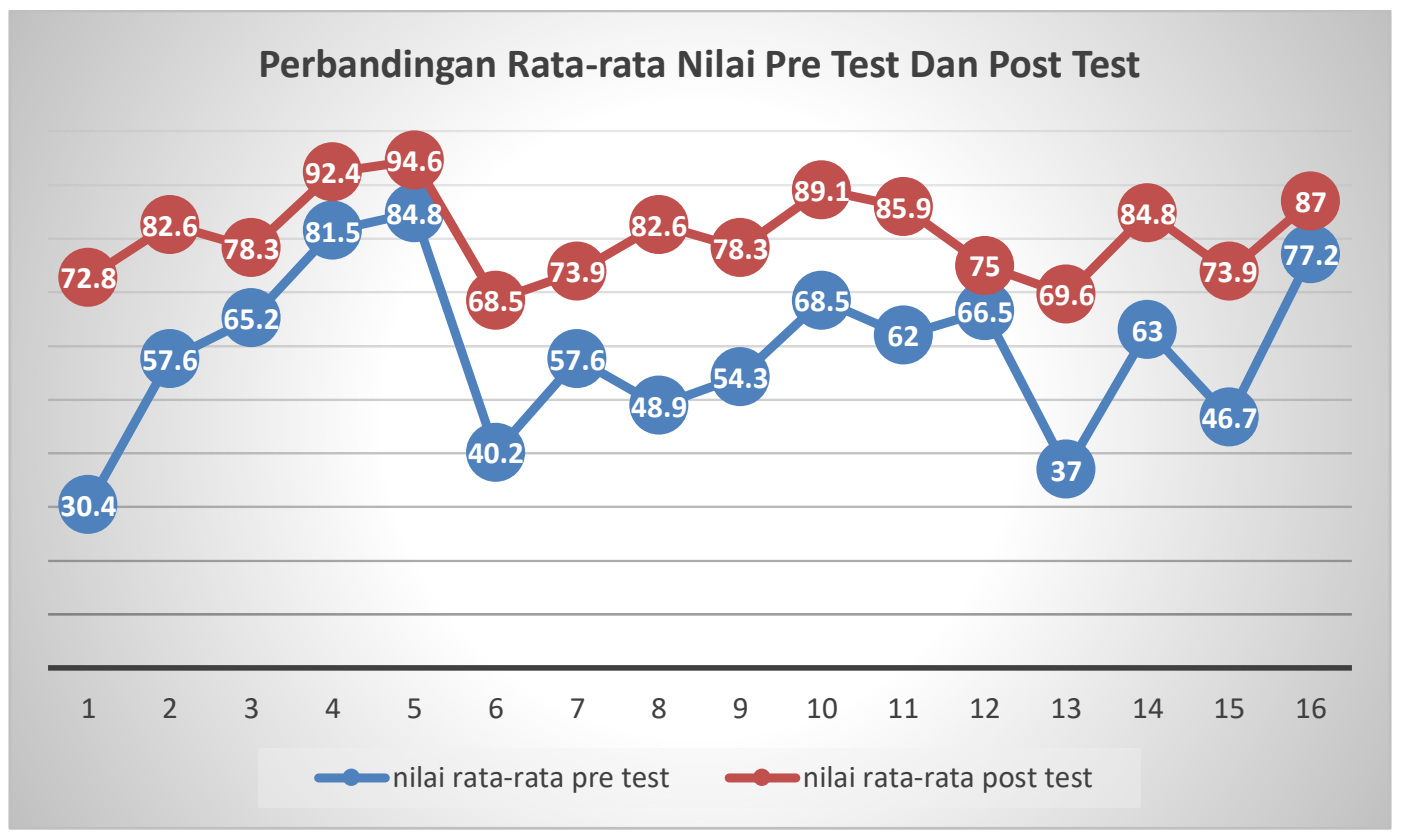

Gambar 7. Perbandingan Nilai Pre Test Dan Post Test Pada Beta Testing

Berdasarkan pengujian pada Beta testing untuk hasil pre test dan dan post test, terdapat rata-rata peningkatan pemahaman mahasiswa tentang topologi jaringan dari semula 58.8 menjadi 80.6, dengan kata lain terdapat kenaikan dari sebelum menggunakan media pembelajaran berbasis AR. Hal lain yang dapat diperhatikan bahwa untuk rata-rata nilai per item pertanyaan mengalami kenaikan dan tidak ada lagi item pertanyaan yang meiliki skor dibawah 60. Dengan adanya kenaikan hasil antara sebelum dan sesudah menggunakan media pembelajaran berbasis AR, maka bisa dikatakan bahwa penerapan AR layak diimplementasikan untuk mendukung pembelajaran pada program studi Teknik Informatika Universitas Abdurrab, khususnya pada matakuliah Jaringan komputer dan pembahasan mengenai topologi jaringan. Namun kenaikan hasil ini tidak menutup kemungkinan untuk dilakukan evaluasi, terurama pada media pembelajaran yang telah dirancang agar evaluasi selanjutnya bisa mendapatkan hasil yang lebih baik lagi.

\section{KESIMPULAN}

Perancangan simulasi topologi jaringan berbasis AR bertujuan sebagai media pembelajaran agar para mahasiswa dapat mengatahui gambaran topologi jaringan komputer dengan lebih jelas, mudah untuk dipahami, dan mahasiswa dapat mengetahui implementasi dari topologi yang diajarkan. Dengan menggunakan tools seperti Vuforia SDK dan Unity 3D, simulasi topologi jaringan komputer dapat dirancang. Hasilnya dapat dilihat bahwa terjadi kenaikan hasil pada post test yang sebelumnya 58.8 menjad 80.6 , hal ini menunjukkan bahwa teknologi AR dapat membantu untukk menciptakan media pembelajaran yang lebih efektif.

\section{UCAPAN TERIMA KASIH}

Penulis mengucapkan terimakasih kepada Segenap jajaran Fakultas Teknik dan Program Studi Teknik Informatika Universitas Abdurrab atas dukungan yang diberikan kepada peneliti. Serta tak lupa para mahasiswa Program Studi Teknik Informatika yang telah bersedia meluangkan waktunya untuk berpartisipasi dalam pengambilan data pada penelitian ini. 
1496 Perancangan Media Pembelajaran Topologi Jaringan dengan Augmented Reality di Program Studi Teknik Informatika - Diki Arisandi, Debi Setiawan, Karpen, Muhammad Musyafak

DOI: https://doi.org/10.31004/edukatif.v4i1.2231

\section{DAFTAR PUSTAKA}

Adiarsi, G. R., Stellarosa, Y., \& Silaban, M. W. (2015). Literasi Media Internet di Kalangan Mahasiswa. Humaniora, 6(4), 470. https://doi.org/10.21512/humaniora.v6i4.3376

Adiputri, L. C., Fauzan, M. N., \& Riza, N. (2020). Tutorial Pembuatan Protipe Prediksi Ketinggian Air (PKA) Dan Augmented Reality Berbasis IoT Versi 2 (Vol. 2). Bandung: Kreatif Industri Nusantara.

Ananda, R., \& Fadhli, M. (2018). Statistik Pendidikan (Teori dan Praktik dalam Pendidikan) (Vol. 1). Medan: Cv. Widya Puspita.

Anggraini, Y., \& Sunaryantiningsih, I. (2018). Pengembangan Media Pembelajaran Pengukuran Listrik Berbasis "Augmented Reality" pada Mahasiswa Teknik Elektro UNIPMA. Jupiter (Jurnal Pendidikan Teknik Elektro), 3(1), 37. https://doi.org/10.25273/jupiter.v3i1.2386

Art., G. Y. (2017). Mobile Phone: Sejarah, Tuntutan Kebutuhan Komunikasi, Hingga Prestise. Alhadharah, 15(30), 1. https://doi.org/10.18592/alhadharah.v15i30.1222

Damardono, A., \& Kautsar, I. A. (2020). Exploration Media of Muhammadiyah University of Sidoarjo with Mixed Reality. JOINCS (Journal of Informatics, Network, and Computer Science), 3(1).

https://doi.org/10.21070/joincs.v3i0.717

Endra, R. Y., \& Agustina, D. R. (2019). Media Pembelajaran Pengenalan Perangkat Keras Komputer Menggunakan Augmented Reality. EXPERT: Jurnal Manajemen Sistem Informasi Dan Teknologi, 9(2), 63-69. https://doi.org/10.36448/jmsit.v9i2.1311

Ernawati, R. S., Hidayat, E. W., \& Rahmatulloh, A. (2017). Implementasi Teknologi Augmented Reality Sebagai Media Pengenalan Aksara Sunda Berbasis Android. Jurnal Teknik Informatika Dan Sistem Informasi, 3(3), 512-523. https://doi.org/10.28932/jutisi.v3i3.671

Indrajit, R. E. (2000). Manajemen sistem informasi dan teknologi informasi. In PT Elex Media Komputindo. Jakarta.

Kamelia, L. (2019). Perkembangan Teknologi Augmented Reality Sebagai Media Pembelajaran Interaktif Pada Mata Kuliah Kimia Dasar. Jurnal Istek, IX(1), 1.

Krisnawati, D. (2018). Peran perkembangan teknologi digital pada strategi pemasaran dan jalur distribusi UMKM di indonesia (Studi kasus: UMKM kuliner tanpa restaurant 'kepiting nyinyir'). Jurnal Manajemen Bisnis Krisnadwipayana, 6(1), 2338-4794.

Kurniawan, I. (2012). Aplikasi Augmented Reality Untuk Pembelajaran Hardware Di Stmik Widya Pratama Pekalongan. Jurnal Ilmiah ICTech, x(2), 1-7.

Masri, M., \& Lasmi, E. (2018). Perancangan Media Pembelajaran Tata Surya Menggunakan Teknologi Augmented Reality Dengan Metode Markerless. Journal of Electrical Technology, 3(3), 40-47. Retrieved from www.kajianpustaka.com

Mustika, Ceppi Gustiar, R., Rheno, S., \& Sofyan. (2015). Implementasi Augmented Reality Sebagai Media Pembelajaran Interaktif. Citec Journal, 2(4), 277-291.

Nissa, S. F., \& Renoningtyas, N. (2021). Penggunaan Media Pembelajaran Wordwall untuk Meningkatkan Minat dan Motivasi Belajar Siswa pada Pembelajaran Tematik di Sekolah Dasar. Edukatif: Jurnal Ilmu Pendidikan, 3(5), 2854-2860. Retrieved from https://edukatif.org/index.php/edukatif/article/view/880

Nugraha, F. A., Nur'aeni, E., Suryana, Y., \& Muharram, M. R. W. (2021). Efektivitas Media Powerpoint dalam Pembelajaran Materi Luas Daerah Segitiga untuk Meningkatkan Minat Belajar Peserta Didik di Sekolah Dasar. Edukatif: Jurnal Ilmu Pendidikan, 3(5), 2760-2768. Retrieved from https://edukatif.org/index.php/edukatif/article/view/931

Oka, G. P. A. (2017). Media dan multimedia pembelajaran. Yogyakarta: DeePublish.

Riyanto, S., \& Hatmawan, A. A. (2020). Metode Riset Penelitian Kuantitatif Penelitian Di Bidang Manajemen, Teknik, Pendidikan Dan Eksperimen. Deepublish. 
1497 Perancangan Media Pembelajaran Topologi Jaringan dengan Augmented Reality di Program Studi Teknik Informatika - Diki Arisandi, Debi Setiawan, Karpen, Muhammad Musyafak

DOI: https://doi.org/10.31004/edukatif.v4i1.2231

Salamun, S., Arisandi, D., Elvitaria, L., \& Trisnawati, L. (2021). A Testing of Case-Base Reasoning for Covid-19 Patient Status Confirmation. Indonesian Journal of Artificial Intelligence and Data Mining (IJAIDM), 4(2), 72-78.

Salamun, S., Arisandi, D., Sukri, S., Jusman, Y., Sari, I. P., \& Elvitaria, L. (2021). Analysis of Beta Testing Performance for Lecturer Monitoring System. 2021 1st International Conference on Electronic and Electrical Engineering and Intelligent System (ICE3IS), 160-164. IEEE.

Uliontang, U., Setyati, E., \& Chandra, F. H. (2020). Pemanfaatan Augmented Reality pada Media Pembelajaran Sejarah Tentang Benda-Benda Bersejarah Peninggalan. Teknika : Engineering and Sains Journal, 4(1), 19-26. 